Edith Cowan University

Research Online

ECU Publications 2011

2011

\title{
Highly bismuth-substituted, record-performance magneto-optic garnet materials with low coercivity for applications in integrated optics, photonic crystals, imaging and sensing
}

\author{
Mohammad Nur E Alam \\ Edith Cowan University \\ Mikhail Vasiliev \\ Edith Cowan University \\ Viacheslav A Kotov \\ Kamal Alameh \\ Edith Cowan University
}

Follow this and additional works at: https://ro.ecu.edu.au/ecuworks2011

Part of the Physical Sciences and Mathematics Commons

10.1364/OME.1.000413

This is an Author's Accepted Manuscript of: Nur E Alam, M. , Vasiliev, M. , Kotov, V., \& Alameh, K. (2011). Highly bismuth-substituted, record-performance magneto-optic garnet materials with low coercivity for applications in integrated optics, photonic crystals, imaging and sensing. Optical Material Express, 1(3), 413-427. Available here (C) 2011 Optical Society of America. One print or electronic copy may be made for personal use only. Systematic reproduction and distribution, duplication of any material in this paper for a fee or for commercial purposes, or modifications of the content of this paper are prohibited.

This Journal Article is posted at Research Online.

https://ro.ecu.edu.au/ecuworks2011/181 


\title{
Highly bismuth-substituted, record-performance magneto-optic garnet materials with low coercivity for applications in integrated optics, photonic crystals, imaging and sensing
}

\author{
Mohammad Nur-E-Alam, ${ }^{1, *}$ Mikhail Vasiliev, ${ }^{1}$ Viacheslav A. Kotov, ${ }^{2}$ and Kamal \\ Alameh ${ }^{1,3}$ \\ ${ }^{1}$ Electron Science Research Institute, Edith Cowan University, 270 Joondalup Drive, Joondalup, WA, 6027, \\ Australia \\ ${ }^{2}$ Institute of Radio Engineering and Electronics, Russian Academy of Sciences, 11 Mohovaya St, Moscow, 125009 , \\ Russia \\ ${ }^{3}$ Department of Nanobio Materials \& Electronics, Gwangju Institute of Science and Technology, South Korea \\ *m.nur-e-alam@ecu.edu.au
}

\begin{abstract}
We report on the fabrication of radio frequency (RF) sputtered Bi-substituted lutetium iron garnet films doped with aluminum and the results of adjusting the properties of these films by means of co-sputtering deposition using an additional bismuth oxide target. Very attractive optical, magnetic and magneto-optical properties are achieved in these new magneto-optic materials. The high-performance magnetically-soft thin-film engineered materials synthesized have a wide range of potential applications in next-generation integrated optics, magneto-photonics and magnetic field sensors.
\end{abstract}

(C)2011 Optical Society of America

OCIS codes: (160.3820) Magneto-optical materials; (310.3840) Materials and process characterization; (130.3130) Integrated optics materials

\section{References and links}

1. A. K. Zvezdin and V. A. Kotov, in Modern Magnetooptics and Magnetooptical Materials (Bristol, Institute of Physics Publishing, and Philadelphia), ISBN 075030362X, 1997.

2. C. F. Buhrer, "Faraday Rotation and Dichroism of Bismuth Calcium Vanadium Iron Garnet," J. Appl. Phys. 40(11), 4500-4502 (1969).

3. G. B. Scott and D. E. Lacklison, "Magnetooptic Properties and Applications of Bismuth Substituted Iron Garnets,” IEEE Trans. Magn. 12(4), 292-311 (1976).

4. T. Hibiya, Y. Morishige, and J. Nakashima, "Growth and Characterization of Liquid-Phase Epitaxial BiSubstituted Iron Garnet Films for Magneto-Optic Application,” Jpn. J. Appl. Phys. 24, 1316-1319 (1985).

5. T. Okuda, N. Koshizuka, K. Hayashi, T. Takahashi, H. Kotani, and H. Yamamoto, "Epitaxial growth of Bisubstituted yttrium iron garnet films by ion beam sputtering," Advances in Magneto-Optics, Proc. Int. Symp. Magneto-Optics, J. Magn. Soc. Jpn. 11, Supplement S1, 179-182 (1987).

6. Y. H. Kim, J. S. Kim, S. I. Kim, and M. Levy, "Epitaxial Growth and Properties of Bi-Substituted Yttrium-IronGarnet Films Grown on (111) Gadolinium-Gallium-Garnet Substrates by Using rf Magnetron Sputtering," J. Korean Phys. Soc. 43(3), 400-405 (2003).

7. Y. Okamura, T. Kawakami, and S. Yamamoto, "Sputter epitaxy of cerium yttrium iron garnet films on neodymium gallium garnet substrates," J. Appl. Phys. 81(8), 5653-5655 (1997).

8. M. Gomi, T. Tanida, and M. Abe, "RF Sputtering of Highly Bi-substituted Garnet Films on Glass Substrates for Magneto-Optic Memory,” J. Appl. Phys. 57(8), 3888-3890 (1985).

9. S. Kang, S. Yin, V. Adyam, Q. Li, and Y. Zhu, " $\mathrm{Bi}_{3} \mathrm{Fe}_{4} \mathrm{Ga}_{1} \mathrm{O}_{12}$ Garnet Properties and Its Application to Ultrafast Switching in the Visible Spectrum," IEEE Trans. Magn. 43(9), 3656-3660 (2007).

10. S. Kahl, A. M. Grishin, S. I. Khartsev, K. Kawano, and J. S. Abell, " $\mathrm{Bi}_{3} \mathrm{Fe}_{5} \mathrm{O}_{12}$ Thin Film Visualizer," IEEE Trans. Magn. 37(4), 2457-2459 (2001).

11. M. Vasiliev, P. C. Wo, K. Alameh, P. Munroe, Z. Xie, V. A. Kotov, and V. I. Burkov, "Microstructural characterization of sputtered garnet materials and all-garnet magnetic heterostructures: establishing the technology for magnetic photonic crystal fabrication,” J. Phys. D Appl. Phys. 42(13), 135003 (2009). 
12. A. K. Bandyopadhyay, S. E. Rios, S. Fritz, J. Garcia, J. Contreras, and C. J. Gutierrez, "Ion Beam SputterFabrication of Bi-YIG Films for Magnetic Photonic Applications,” IEEE Trans. Magn. 40(4), 2805-2807 (2004).

13. M. Vasiliev, M. N. Alam, V. A. Kotov, K. Alameh, V. I. Belotelov, V. I. Burkov, and A. K. Zvezdin, "RF magnetron sputtered (BiDy)3(FeGa)5O12:Bi2O3 composite garnet-oxide materials possessing record magnetooptic quality in the visible spectral region," Opt. Express 17(22), 19519-19535 (2009).

14. I. L. Lyubchanskii, N. N. Dadoenkova, M. I. Lyubchanskii, E. A. Shapovalov, and Th. Rasing, "Magnetic photonic crystals," J. Phys. D Appl. Phys. 36(18), R277-R287 (2003).

15. M. Vasiliev, K. Alameh, V. Belotelov, V. A. Kotov, and A. K. Zvezdin, “"Magnetic Photonic Crystals: 1-D Optimization and Applications for the Integrated Optics Devices," IEEE/OSA,” J. Lightwave Technol. 24(5), 2156-2162 (2006).

16. M. J. Steel, M. Levy, and R. M. Osgood, "High Transmission Enhanced Faraday Rotation in One-Dimensional Photonic Crystals with Defects," IEEE Photon. Technol. Lett. 12(9), 1171-1173 (2000).

17. M. Vasiliev, V. A. Kotov, K. E. Alameh, V. I. Belotelov, and A. K. Zvezdin, "Novel Magnetic Photonic Crystal Structures for Magnetic Field Sensors and Visualizers," IEEE Trans. Magn. 44(3), 323-328 (2008).

18. M. Nur-E-Alam, M. Vasiliev, and K. Alameh, Nano-structured magnetic photonic crystals for magneto-optic polarization controllers at the communication-band wavelengths," Opt. Quantum Electron. 41(9), 661-669 (2009).

19. P. Tierno, F. Sagués, T. H. Johansen, and T. M. Fischer, "Colloidal transport on magnetic garnet films," Phys. Chem. Chem. Phys. 11(42), 9615-9625 (2009).

20. A. Abdelrahman, M. Vasiliev, K. Alameh, and P. Hannaford, "Asymmetrical two-dimensional magnetic lattices for ultracold atoms," Phys. Rev. A 82(1), 012320 (2010).

21. A. H. Eschenfelder, Magnetic Bubble Technology (Springer-Verlag, New York, ISBN 3-540-09822-4), 1980.

22. N. Adachi, K. Obata, T. Okuda, T. Machi, and N. Koshizuka, "Synthesis of Bi-Lu-substituted Iron Garnet Films for Visualization of Magnetic Flux in High-Tc Superconductors,” Jpn. J. Appl. Phys. 41 (Part1, 10), 5986-5990 (2002).

23. M. Vasiliev, M. Nur-E-Alam, K. Alameh, P. Premchander, Y. T. Lee, V. A. Kotov, and Y. P. Lee, Annealing behaviour and crystal structure of RF-sputtered Bi-substituted dysprosium iron-garnet films having excess cosputtered Bi-oxide content," J. Phys. D Appl. Phys. 44(7), 075002 (2011).

24. J. P. Krumme, V. Doormann, B. Strocka, and P. Willich, "Selected-area sputter epitaxy of iron-garnet films," J. Appl. Phys. 60(6), 2065-2068 (1986).

25. T. Mizumoto, S. Mashimo, T. Ida, and Y. Naito, "In-plane Magnetized Rare Earth Iron Garnet for a Waveguide Optical Isolator Employing Nonreciprocal Phase Shift,” IEEE Trans. Magn. 29(6), 3417-3419 (1993).

\section{Introduction}

In recent years significant improvements have been achieved in the area of thin film materials synthesis for various emerging optical applications and technologies. Rare-earth doped materials (for example, various oxides and garnets) are very promising for the applications in optical technologies such as planar optical waveguides, optical amplifiers and isolators. Different types of materials containing rare-earth atoms have been investigated in detail and used for various applications, but the rare-earth-substituted iron garnets, especially the Bisubstituted rare-earth iron garnet materials are of high importance for a wide range of applications due to their extra-ordinary magneto-optical (MO) properties and high transparency in parts of visible and also across the entire near-infrared spectral range. Bisubstituted iron garnet thin film materials are one of the best transparent MO materials possessing the giant MO properties. Since 1960 Bi:IGs' of different compositions containing different metal dopants have been produced and their properties have been studied extensively to realise their potential in various new and existing technologies [1-9]. Bi:IGs are still considered to be the best materials for use in non-reciprocal optical components, magnetic recording, magnetic field sensing and imaging as well as for applications in magnetically-tunable photonic crystal devices. There exists a wide (and growing) range of applications of epitaxial (monocrystalline) and also nanocrystalline MO garnet films of various compositions and deposited onto different substrate types [8-21]. In a number of important application areas, low-coercivity films with either the in-plane-oriented easy axis of magnetization or having a strong in-plane magnetization component and at the same time possessing very high MO quality are required. Multiple variations in the material properties of garnets are required for different applications in integrated optics and in photonics, and these can be engineered by adjusting the material composition. This work is devoted to the 
synthesis and characterisation of highly $\mathrm{Bi}$-substituted lutetium iron garnet thin films of composition type $(\mathrm{BiLu})_{3}(\mathrm{FeAl})_{5} \mathrm{O}_{12}$ featuring a strong in-plane magnetization component and magnetically-soft switching behavior. Previous work on the synthesis of monocrystalline films of a similar composition type using a different technology has been reported by Adachi et al in 2002 [22]. They reported on the preparation of $(\mathrm{BiLu})_{3}(\mathrm{FeGa})_{5} \mathrm{O}_{12}$ garnet films by the liquid-phase epitaxy (LPE) technique, and their monocrystalline layers were also postannealed at high temperatures to obtain the in-plane magnetic anisotropy. The resulting inplane magnetized thin-film materials possessed the properties suitable for magnetic flux visualization in high- $T_{c}$ superconductors. LPE is the most commonly-used technology that enables growth of monocrystalline Bi-substituted garnet films on various monocrystalline garnet substrates, but it requires clean-room conditions and a range of complex process equipment. In LPE, the achievable Bi substitution levels are rather limited, and the layer growth occurs invariably on both substrate sides, which can limit the range of possible applications of such films. RF magnetron sputtering is one of the ideal alternatives to produce high-quality Bi-substituted iron garnet films, which however are poly- or nanocrystalline [11]. RF magnetron sputtering is also suitable for the integration of garnet layers of controllable composition into existing integrated-optic components and circuits. It is possible to obtain very high MO quality (of the world-record standard) and also very small garnet grain size of 40-50 nm in RF-sputtered films which are brought into the ferrimagnetic garnet phase by means of high-temperature heat treatment $[11,13,23]$. Sputter epitaxy processes are also possible, provided that very accurate lattice-matching is ensured and when using finelyoptimized process conditions and high substrate temperatures that ensure in situ crystal growth during the deposition [7,24].

The methods for the calculation of the expected crystal lattice parameters of doped irongarnet materials containing various rare-earth and metal-ion substitutions have been described in detail in [21]. For example, the cubic lattice parameter $a$ of a garnet layer of composition type described by the formula $(\mathrm{BiLu})_{3}(\mathrm{FeAl})_{5} \mathrm{O}_{12}$ can be predicted from the layer stoichiometry by using the following Eq. (1).

$$
a(A)=12.376+0.0828 * B i[f . u .]-0.031 * L u[f . u .]-0.0741 * A l[f . u .]
$$

where f.u. (formula units) is the number of atoms of each corresponding element substituted into the garnet lattice (the calculation is based on evaluating the effects of substituting each of the atom types shown into the yttrium-iron garnet lattice of parameter $12.376 \AA$ ). We found, using Eq. (1), that a garnet material with a composition described by the formula $\mathrm{Bi}_{1.8} \mathrm{Lu}_{1.2} \mathrm{Fe}_{3.6} \mathrm{Al}_{1.4} \mathrm{O}_{12}$ is expected to have a lattice parameter of $12.384 \AA$ and would therefore represent a material engineered for almost-perfect lattice-matching with gadolinium gallium garnet (GGG) substrates, which have a lattice parameter of $12.383 \AA$. High-crystalline-quality iron-garnet materials with high $\mathrm{Bi}$ substitutions typically possess crystal lattice parameters exceeding that of GGG significantly and have been deposited so far mostly onto specialized and somewhat rare large-parameter substrate types, like GSGG. In addition, it is rather difficult to obtain garnet-phase layers with $\mathrm{Bi}$ substitutions being as large as $1.8 \mathrm{f}$.u. using LPE processes, however RF sputtering of such materials from oxide-mix-based targets has been demonstrated successfully [13]. This has opened the way for the development of closely substrate-matched and highly-Bi-substituted garnet layers exhibiting very strong specific Faraday rotation and strong in-plane magnetization component (weak uniaxial magnetic anisotropy) simultaneously.

The goal of this work is to investigate and compare the properties and the practicality of these lattice-engineered garnet films sputtered onto GGG (111) and also the glass substrates (Corning Eagle XG). To the best of our knowledge, no characterization data on the sputterdeposited garnet material of this particular composition could be found in the literature published to date. We report the results of optimizing the oven-annealing regimes as well as

\#147538 - \$15.00 USD Received 13 May 2011; revised 8 Jun 2011; accepted 12 Jun 2011; published 17 Jun 2011

(C) 2011 OSA 1 July 2011 / Vol. 1, No. 3 / OPTICAL MATERIALS EXPRESS 415 
on the optical, magnetic and magneto-optical properties of $\mathrm{Bi}_{1.8} \mathrm{Lu}_{1.2} \mathrm{Fe}_{3.6} \mathrm{Al}_{1.4} \mathrm{O}_{12}$ films, which are found to be very attractive for various optical and magneto-optical applications in nonreciprocal integrated optics, magneto-photonic crystals and waveguides, magnetic field imaging and sensing devices. Experimental results confirm our hypothesis which states that the co-sputtering approach (using an additional bismuth oxide target) will lead to improving the MO quality of garnet films for this material type similarly to the results reported in $[13,23]$.

\section{Materials Synthesis and Characterization Techniques}

We fabricated highly $\mathrm{Bi}$-substituted lutetium iron-aluminum garnet and also garnet- $\mathrm{Bi}_{2} \mathrm{O}_{3}$ nanocomposite layers of different thicknesses using RF magnetron sputtering technology. The oxide-mix-based sputtering target (AJA Inc., USA) of nominal stoichiometry $\mathrm{Bi}_{1.8} \mathrm{Lu}_{1.2} \mathrm{Fe}_{3.6} \mathrm{Al}_{1.4} \mathrm{O}_{12}$ and a separate $\mathrm{Bi}_{2} \mathrm{O}_{3}$ target were used to produce the amorphous thin films of garnet-type stoichiometry. The targets were prepared using high-purity materials (99.9\% for the oxide-mix-based $\mathrm{Bi}_{1.8} \mathrm{Lu}_{1.2} \mathrm{Fe}_{3.6} \mathrm{Al}_{1.4} \mathrm{O}_{12}$ and $99.999 \%$ for $\mathrm{Bi}_{2} \mathrm{O}_{3}$ ). The target's composition was selected based on our previous observations of nearly-perfect stoichiometry transfer from similar mixed-oxide garnet-type targets to the growing film layers in processes using low $\left(250{ }^{\circ} \mathrm{C}\right)$ substrate temperatures. $\mathrm{Bi}_{1.8} \mathrm{Lu}_{1.2} \mathrm{Fe}_{3.6} \mathrm{Al}_{1.4} \mathrm{O}_{12}$ garnet films were deposited onto glass and GGG (111) substrates using a range of substrate temperatures between 250 and $680{ }^{\circ} \mathrm{C}$, whilst the garnet-oxide composite films having different added volumes of extra $\mathrm{Bi}_{2} \mathrm{O}_{3}$ were all prepared at $250{ }^{\circ} \mathrm{C}$ substrate temperature.

During the sputtering processes, we used low-pressure pure-argon (Ar) plasma; the details of sputtering process conditions used are summarized in Table 1 . The targets were always pre-sputtered for 10-20 minutes before depositing the films onto the substrates to achieve stable process conditions. The film thicknesses were monitored during the deposition processes using in situ laser reflectometry. The film thicknesses were also re-measured after the deposition using their transmission spectra obtained with a UV/visible spectrophotometer and our thickness-fitting software [13].

Table 1. Sputtering Parameters and Process Conditions Used for the Deposition of

Magneto-Optic $\mathrm{Bi}_{1.8} \mathrm{Lu}_{1.2} \mathrm{Fe}_{3.6} \mathrm{Al}_{1.4} \mathrm{O}_{12}$ Garnet Layers and Garnet-Bismuth Oxide Nanocomposite Derivatives

\begin{tabular}{|l|l|}
\hline Sputtering targets composition & $\mathrm{Bi}_{1.8} \mathrm{Lu}_{1.2} \mathrm{Fe}_{3.6} \mathrm{Al}_{1.4} \mathrm{O}_{12}$ and $\mathrm{Bi}_{2} \mathrm{O}_{3}$ \\
\hline Target size & $3^{\prime \prime}($ diameter$)$ with the material layer thickness of $1 / 8^{\prime \prime}$ \\
\hline Background Pressure & $\mathrm{P}($ base $)<1-2 \cdot 10^{-6}$ Torr \\
\hline Process gas and pressure & Argon, $\mathrm{P}(\mathrm{Ar})=1 \mathrm{mTorr}$ \\
\hline RF power density at targets & Typically $3.7 \mathrm{~W} / \mathrm{cm}^{2}(170 \mathrm{~W})$ for garnet and \\
& $0.22-0.55 \mathrm{~W} / \mathrm{cm}^{2}(10-25 \mathrm{~W})$ for $\mathrm{Bi}_{2} \mathrm{O}_{3}$ \\
\hline Substrate-target distance & $18-20 \mathrm{~cm}$ \\
\hline Substrate temperature during & $250-680{ }^{\circ} \mathrm{C}$, typ. $250{ }^{\circ} \mathrm{C}$ \\
deposition & \\
\hline Substrate types & Glass $($ Corning Eagle $\mathrm{XG})$ and monocrystalline GGG (111) \\
\hline Deposition rates & $4-6 \mathrm{~nm} / \mathrm{min}$ for garnet; \\
& $0.7-1.3 \mathrm{~nm} / \mathrm{min}$ for $\mathrm{Bi}_{2} \mathrm{O}_{3}$ \\
\hline
\end{tabular}

A conventional box-furnace-type oven system was used to run the annealing processes for our as-deposited (amorphous) garnet and garnet-oxide thin films. We also performed the annealing heat treatment at a range of different temperatures for one particular batch of garnet-oxide composite thin films and evaluated the annealing effects on the optical and MO properties of our garnet-oxide nanocomposite materials. The optical and MO performance of 
thin film garnet materials was found to be critically dependent on the annealing temperature and also the process duration used. The annealing processes were run for $\mathrm{Bi}_{1.8} \mathrm{Lu}_{1.2} \mathrm{Fe}_{3.6} \mathrm{Al}_{1.4} \mathrm{O}_{12}$ garnet thin films in between a range of temperatures $620-700^{\circ} \mathrm{C}$, with $3-5{ }^{\circ} \mathrm{C} / \mathrm{min}$ temperature ramp-up and ramp-down rates, for a number of different annealing durations. The $3^{\circ} \mathrm{C} / \mathrm{min}$ temperature-ramp rate resulted in micro-crack-free film surfaces observed in films sputtered onto both substrate types. $\mathrm{Bi}_{1.8} \mathrm{Lu}_{1.2} \mathrm{Fe}_{3.6} \mathrm{Al}_{1.4} \mathrm{O}_{12}: \mathrm{Bi}_{2} \mathrm{O}_{3}$ composite films having different vol. $\%$ of extra bismuth oxide were subjected to annealing using a range of temperatures in between 610 and $680{ }^{\circ} \mathrm{C}$ for different annealing process durations. The annealed thin films were characterized optically, magnetically and magneto-optically by deriving their absorption coefficient spectra and measuring the specific Faraday rotation at several wavelengths. The Faraday rotation hysteresis loops were also measured to characterize the magnetic switching properties. The specific Faraday rotation measurements of films were performed using a Thorlabs PAX polarimeter system and an electromagnet, by recording the azimuth directions of the polarization plane of polarized laser light transmitted through samples. A transmission-mode polarization microscope (Leitz Orthoplan) was used to observe the magnetic domain patterns of garnet films generated by the component of the layers' magnetization existing in the direction perpendicular to the film plane. Unlike the $(\mathrm{BiDy})_{3}(\mathrm{FeGa})_{5} \mathrm{O}_{12}$ films studied by us previously in detail [13], the films of composition type $(\mathrm{BiLu})_{3}(\mathrm{FeAl})_{5} \mathrm{O}_{12}$ were magnetically-soft, yet showed the high-contrast domain patterns even after a brief contact with a strong permanent magnet (the materials possessed a low remnant magnetization and did not remain in the monodomain state after being subjected to the saturating field).

\section{Results and Discussion}

\subsection{Properties of Sputtered $\mathrm{Bi}_{1.8} \mathrm{Lu}_{1.2} \mathrm{Fe}_{3.6} \mathrm{Al}_{1.4} \mathrm{O}_{12}$ Garnet Layers on Glass and GGG Substrates}

$\mathrm{Bi}_{1.8} \mathrm{Lu}_{1.2} \mathrm{Fe}_{3.6} \mathrm{Al}_{1.4} \mathrm{O}_{12}$ garnet layers of $(1000 \pm 20) \mathrm{nm}$ thickness were deposited onto glass and GGG substrates. The annealed high-quality thin garnet films were achieved after running the optimized annealing treatments $\left(1\right.$ hour at $650{ }^{\circ} \mathrm{C}$ for films deposited onto GGG substrates and 3 hours at $630{ }^{\circ} \mathrm{C}$ for films on glass substrates). The materials demonstrated an attractive combination of rather high specific Faraday rotation (confirming high Bi substitution levels achieved) and low optical absorption across large parts of the visible spectral range. Very good transparency was observed across the near-infrared range. We derived the absorption coefficient spectrum of the material according to the technique reported in Ref. [16]. Figure 1 shows the typical absorption spectrum of crystallized $\mathrm{Bi}_{1.8} \mathrm{Lu}_{1.2} \mathrm{Fe}_{3.6} \mathrm{Al}_{1.4} \mathrm{O}_{12}$ layers deposited onto GGG (111) substrates, with the upper and lower limits for the absorption coefficients shown. Similar spectra of absorption coefficient were observed on the samples sputtered onto glass (Corning Eagle XG) substrate also. The maximum (measured in optimally-annealed films on GGG substrates) values of Faraday rotation per film thickness of this garnet material type were around $5.9 \mathrm{deg} / \mu \mathrm{m}$ at $532 \mathrm{~nm}, 1.6$ $\mathrm{deg} / \mu \mathrm{m}$ at $635 \mathrm{~nm}$ and $1.07 \mathrm{deg} / \mu \mathrm{m}$ at $660 \mathrm{~nm}$, and the films also had relatively low absorption, which led to high MO figures of merit. 


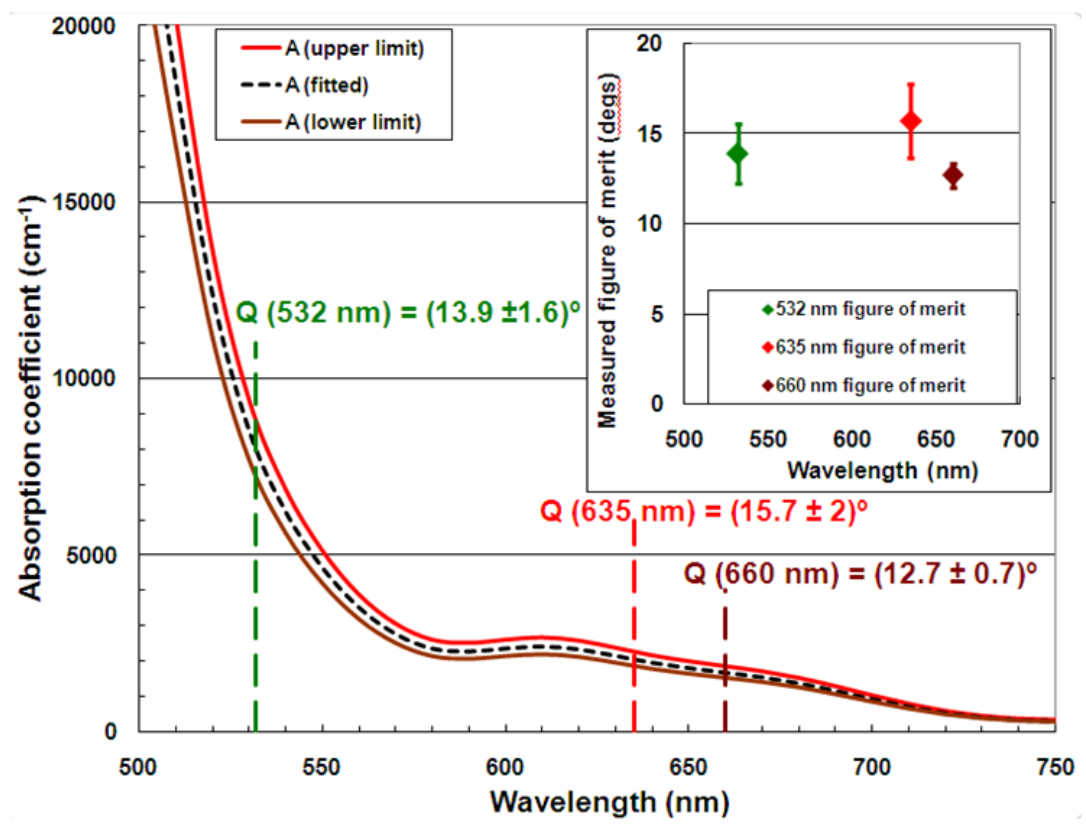

Fig. 1. Derived absorption coefficient spectrum showing the upper (red color) and lower limits (brown color) of $\mathrm{Bi}_{1.8} \mathrm{Lu}_{1.2} \mathrm{Fe}_{3.6} \mathrm{Al}_{1.4} \mathrm{O}_{12}$ garnet films deposited onto GGG (111) substrates and annealed at $650{ }^{\circ} \mathrm{C}$ for $1 \mathrm{~h}$ according to the methodology described in Section II. The data points for the MO figure of merit measured using $532 \mathrm{~nm}, 635 \mathrm{~nm}$ and $660 \mathrm{~nm}$ light with associated error bars are shown in the inset.

These properties, together with their magnetically-soft behavior, make sputtered films of composition $\mathrm{Bi}_{1.8} \mathrm{Lu}_{1.2} \mathrm{Fe}_{3.6} \mathrm{Al}_{1.4} \mathrm{O}_{12}$ very attractive for use in different magneto-optic applications and in novel photonic components, for example in garnet waveguides [25]. We measured the $\mathrm{MO}$ quality factors $\left(2 \theta_{\mathrm{F}} / \alpha\right)$ of $\mathrm{Bi}_{1.8} \mathrm{Lu}_{1.2} \mathrm{Fe}_{3.6} \mathrm{Al}_{1.4} \mathrm{O}_{12}$ garnet layers deposited onto GGG (111) substrates and obtained values of $13.9^{\circ}\left( \pm 1.6^{\circ}\right)$ at $532 \mathrm{~nm}, 15.7^{\circ}\left( \pm 2^{\circ}\right)$ at $635 \mathrm{~nm}$ and $12.7^{\circ}\left( \pm 0.7^{\circ}\right)$ at $660 \mathrm{~nm}$; these values were lower by about $15-20 \%$ in films deposited onto glass.

Figure 2 shows the hysteresis loops of specific Faraday rotation measured at $532 \mathrm{~nm}$ in films sputtered onto GGG (111) and also glass substrates using $250{ }^{\circ} \mathrm{C}$ substrate temperature (a, b) and also the same data for a film deposited onto GGG at $680{ }^{\circ} \mathrm{C}(\mathrm{c})$. The measured coercive force for the films sputtered at $250{ }^{\circ} \mathrm{C}$ on GGG substrates was about 45 Oe, while the coercivity of the films on glass substrates was near 100 Oe (Fig. 2 (a, b)). We observed a much lower coercive force value of below 20 Oe in films on GGG substrates prepared at a higher substrate temperature of $680{ }^{\circ} \mathrm{C}$ (Fig. 2 (c)). During hysteresis measurements, the external magnetic field was applied in the direction perpendicular to the film plane, and parallel to the light propagation direction. The almost-linear character of magnetization curves observed below saturation indicates that a significant component of the film's magnetization lies in the film plane. However, the magnetization vectors of the films on both substrate types also had a perpendicular component, which resulted in the observations of maze-type magnetic domain patterns by polarization microscopy and also using magnetic force microscopy (NT-MDT Nova Scanning Probe Nanolaboratory). 


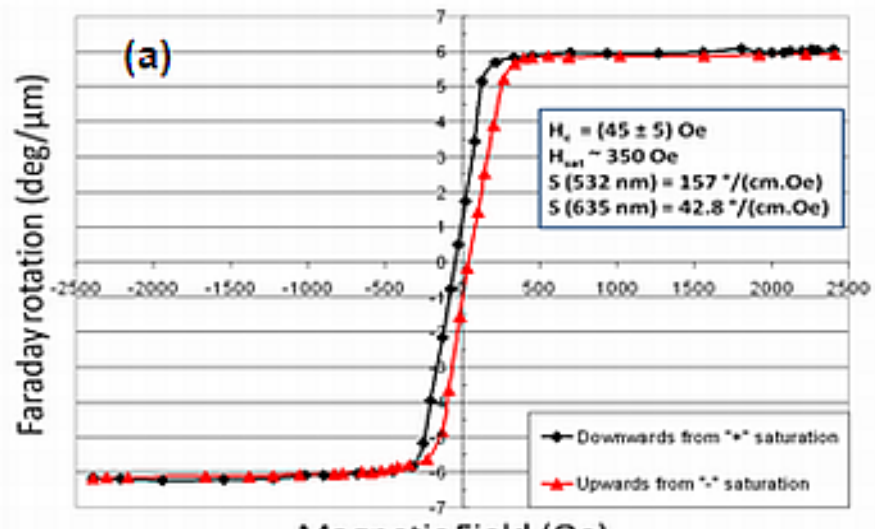

Magnetic Field (Oe)
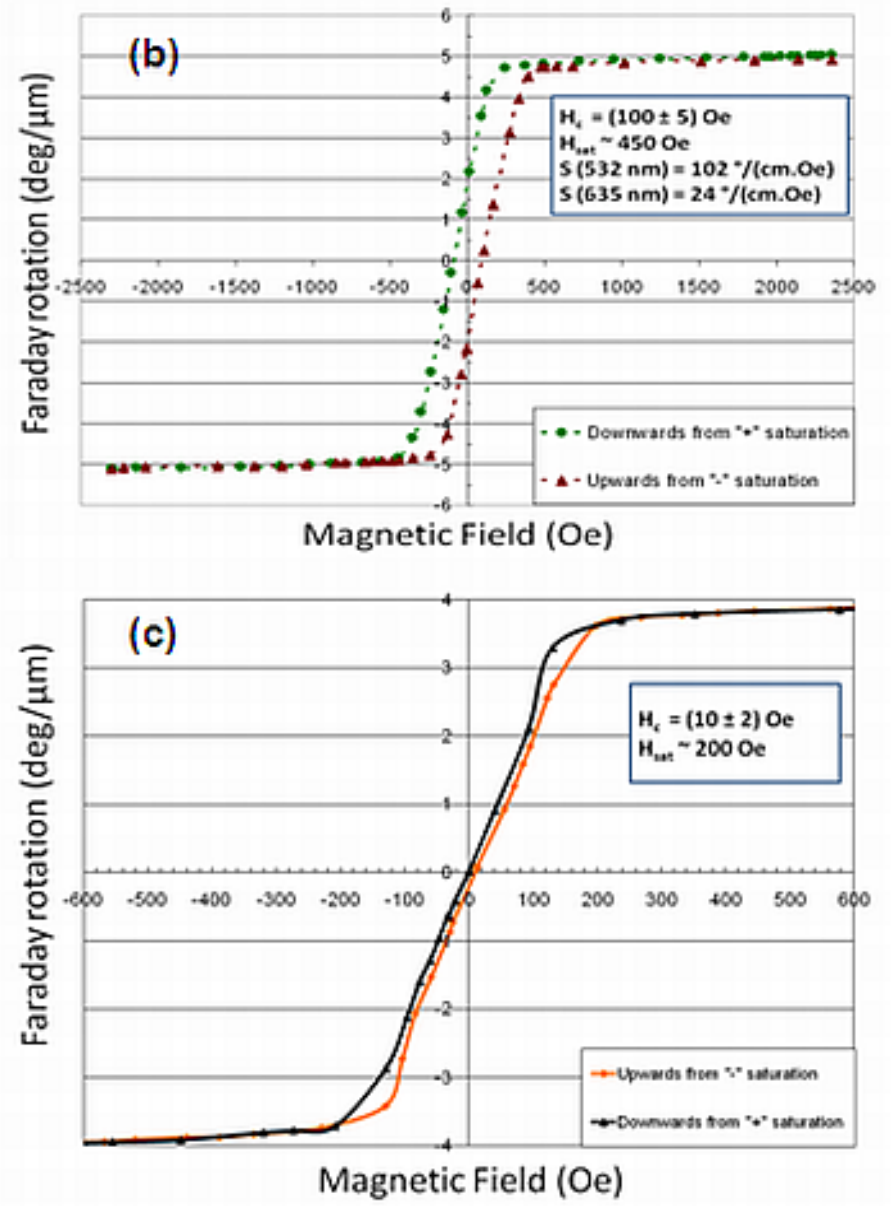

Fig. 2. Hysteresis loops of specific Faraday rotation measured at $532 \mathrm{~nm}$ in sputtered $\mathrm{Bi}_{1.8} \mathrm{Lu}_{1.2} \mathrm{Fe}_{3.6} \mathrm{Al}_{1.4} \mathrm{O}_{12}$ garnet films deposited at $250{ }^{\circ} \mathrm{C}$ onto (a) GGG substrate (annealed for 1 $\mathrm{h}$ at $650{ }^{\circ} \mathrm{C}$ ), (b) glass substrate (annealed for $3 \mathrm{~h}$ at $630{ }^{\circ} \mathrm{C}$ ). Insets show the measured coercive force, saturation field and the magnetic field sensitivity values at 532 and $635 \mathrm{~nm}$ within the linear ranges of magnetization, and (c) hysteresis loop of specific Faraday rotation measured at $532 \mathrm{~nm}$ in sputtered $\mathrm{Bi}_{1.8} \mathrm{Lu}_{1.2} \mathrm{Fe}_{3.6} \mathrm{Al}_{1.4} \mathrm{O}_{12}$ garnet films of $650 \mathrm{~nm}$ deposited onto GGG at $680{ }^{\circ} \mathrm{C}$ substrate temperature annealed for $3 \mathrm{~h}$ at $630^{\circ} \mathrm{C}$. 
Within the linear magnetization range, a rather high Faraday-effect magnetic field sensitivity (the ratio of increments of Faraday rotation to magnetic field) of up to $42.8 \%(\mathrm{~cm} \cdot \mathrm{Oe}$ ) was measured at $635 \mathrm{~nm}$, which even exceeds the previously-reported value of $13 \%(\mathrm{~cm} \cdot \mathrm{Oe})$ measured in epitaxial $(\mathrm{BiLu})_{3}(\mathrm{FeGa})_{5} \mathrm{O}_{12}$ films obtained by LPE [22]. The domain structures observed in our garnet and garnet-oxide composite thin films in the absence of externally applied magnetic fields are shown in Fig. 3. An average domain width of about 1 micron was observed in films of $1 \mu \mathrm{m}$ thickness.
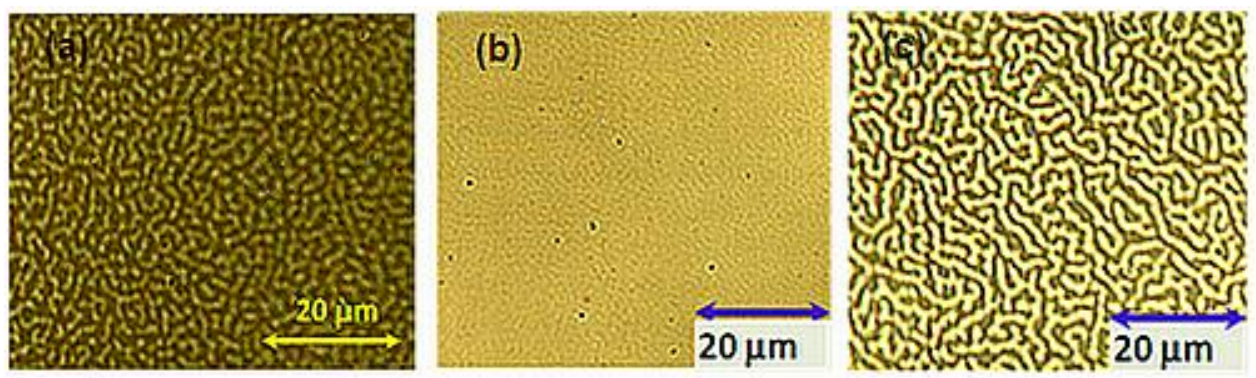

Fig. 3. Regular maze-type domains were observed in sputtered typical $\mathrm{Bi}_{1.8} \mathrm{Lu}_{1.2} \mathrm{Fe}_{3.6} \mathrm{Al}_{1.4} \mathrm{O}_{12}$ garnet films onto GGG deposited onto GGG substrate at (a) $250{ }^{\circ} \mathrm{C} \mathrm{T}$ (sub) (annealed for $1 \mathrm{~h}$ @ $650{ }^{\circ} \mathrm{C}$, (b) $680{ }^{\circ} \mathrm{C} \mathrm{T}$ (sub) (annealed for $3 \mathrm{~h} @ 630{ }^{\circ} \mathrm{C}$ ) and (c) $\mathrm{Bi}_{18} \mathrm{Lu}_{12} \mathrm{Fe}_{36} \mathrm{Al}_{1.4} \mathrm{O}_{12}: \mathrm{Bi}_{2} \mathrm{O}_{3}$ (4.5 vol. \%) composite garnet-oxide films (annealed for $10 \mathrm{hrs} @ 610{ }^{\circ} \mathrm{C}$ ) using the transmission-mode polarization microscope (Leitz Orthoplan) at high magnification (630 X).

The attractive properties of $\mathrm{Bi}_{1.8} \mathrm{Lu}_{1.2} \mathrm{Fe}_{3.6} \mathrm{Al}_{1.4} \mathrm{O}_{12}$ garnet material with magnetically-soft behavior show great promise for the future development of different emerging types of reconfigurable nano-photonic devices. Especially important is the possibility of obtaining garnet films with in-plane magnetization, linear magnetization response and good magnetic and MO properties on non-garnet substrates and without resorting to the use of complex crystal growth technologies.

\subsection{Properties of Co-sputtered $\mathrm{Bi}_{1.8} \mathrm{Lu}_{1.2} \mathrm{Fe}_{3.6} \mathrm{Al}_{1.4} \mathrm{O}_{12}$ : $\mathrm{Bi}_{2} \mathrm{O}_{3}$ Nanocomposite Layers on Glass} and GGG Substrates

$\mathrm{Bi}_{1.8} \mathrm{Lu}_{1.2} \mathrm{Fe}_{3.6} \mathrm{Al}_{1.4} \mathrm{O}_{12}: \mathrm{Bi}_{2} \mathrm{O}_{3}$ nanocomposite layers having different volumetric fractions of extra $\mathrm{Bi}_{2} \mathrm{O}_{3}(4.5-20$ vol. \%) were produced and then crystallized using a high temperature annealing system. The optical and MO properties of all composite films were characterized. Figure 4 shows the transmission spectra of several annealed garnet-oxide composite films of $1050 \mathrm{~nm}$ thickness sputtered onto both glass and garnet substrates measured using a UV/VIS spectrophotometer (Beckman Coulter D 640 B). Non-uniformity effects were not observed after the co-sputter deposition of amorphous oxide-mixed films or after running the annealing heat treatment processes inside the oven. Significantly, lower absorption coefficients were obtained in garnet-oxide composite films across the visible spectral region compared to $\mathrm{Bi}_{1.8} \mathrm{Lu}_{1.2} \mathrm{Fe}_{3.6} \mathrm{Al}_{1.4} \mathrm{O}_{12}$ garnet layers as shown in Fig. 5. The addition of extra bismuth oxide didn't have much impact on the Faraday rotation of the films but it did improve the optical quality noticeably, consequently improving the magneto-optic quality in terms of MO figure of merit up to more than $50^{\circ}$ at $635 \mathrm{~nm}$. 


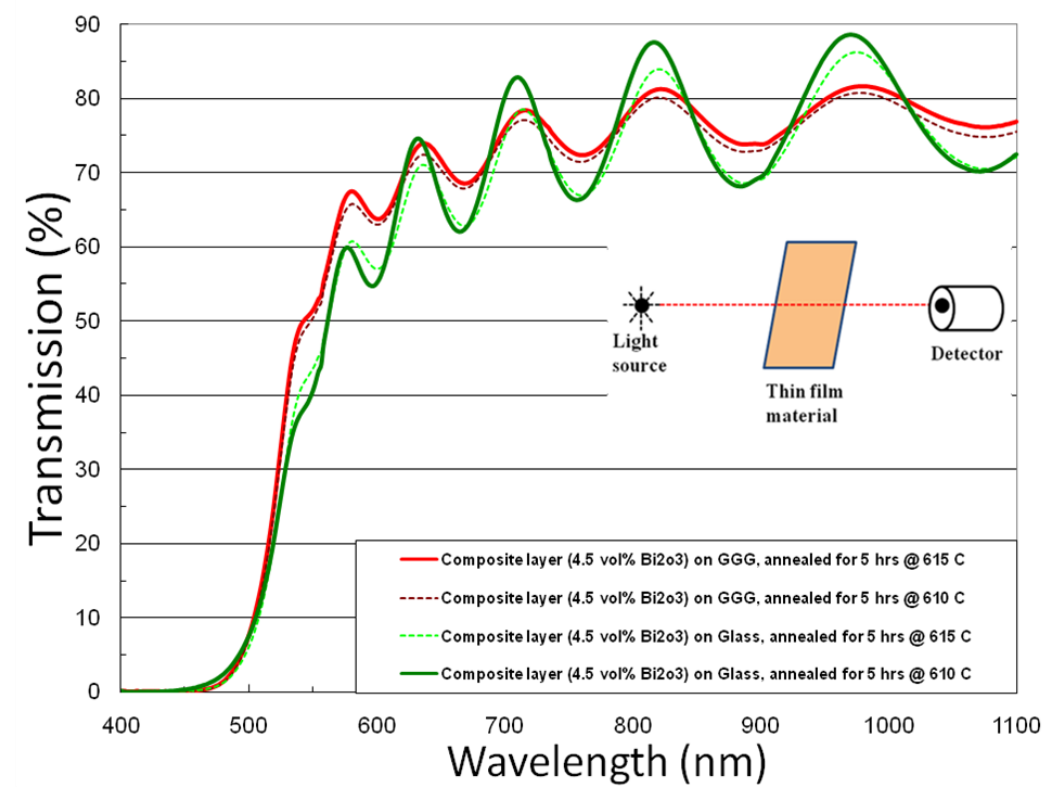

Fig. 4. Transmission spectra of several 1050nm-thick $\mathrm{Bi}_{1.8} \mathrm{Lu}_{1.2} \mathrm{Fe}_{3.6} \mathrm{Al}_{1.4} \mathrm{O}_{12}: \mathrm{Bi}_{2} \mathrm{O}_{3}$ (4.5 vol. \%) composite garnet-oxide layers (samples from the same deposition batch) sputtered onto monocrystalline GGG (111) and also onto glass (Corning Eagle XG) substrates and postdeposition annealed for $5 \mathrm{~h}$ at $610^{\circ} \mathrm{C}$ and at $615^{\circ} \mathrm{C}$; the inset shows a schematic diagram of the power transmission spectrum measurement using a UV/VIS spectrophotometer. The measured percentage of the incident optical power transmitted through the substrate/film system is plotted (no additional normalization with respect to the blank substrate transmission was applied).

The optical and MO properties of garnet materials were critically dependent on the optimization of annealing process parameters, and the optimization of all annealing process parameters for each garnet composition type was a time-consuming process since the annealing behavior of films is strongly composition-dependent [13]. $\mathrm{Bi}_{1.8} \mathrm{Lu}_{1.2} \mathrm{Fe}_{3.6} \mathrm{Al}_{1.4} \mathrm{O}_{12}$ : $\mathrm{Bi}_{2} \mathrm{O}_{3}$ (4.5 vol. \% excess bismuth oxide) composite films were annealed using many possible approaches to thermal treatment, and it was found that the optimized annealing temperatures were between 610 and $620{ }^{\circ} \mathrm{C}$ and the optimized time durations varied between 3 and 20 hours. Significant effects of the annealing temperature variation on both the optical and MO properties were observed in this material type. The optimized absorption coefficient spectra achieved in $\mathrm{Bi}_{1.8} \mathrm{Lu}_{1.2} \mathrm{Fe}_{3.6} \mathrm{Al}_{1.4} \mathrm{O}_{12}: \mathrm{Bi}_{2} \mathrm{O}_{3}$ (4.5 vol. \% of excess $\mathrm{Bi}_{2} \mathrm{O}_{3}$ ) garnet-oxide composite films sputtered onto GGG (111) substrates and annealed at $610-620{ }^{\circ} \mathrm{C}$ for different annealing time durations are shown in Fig. 6. 


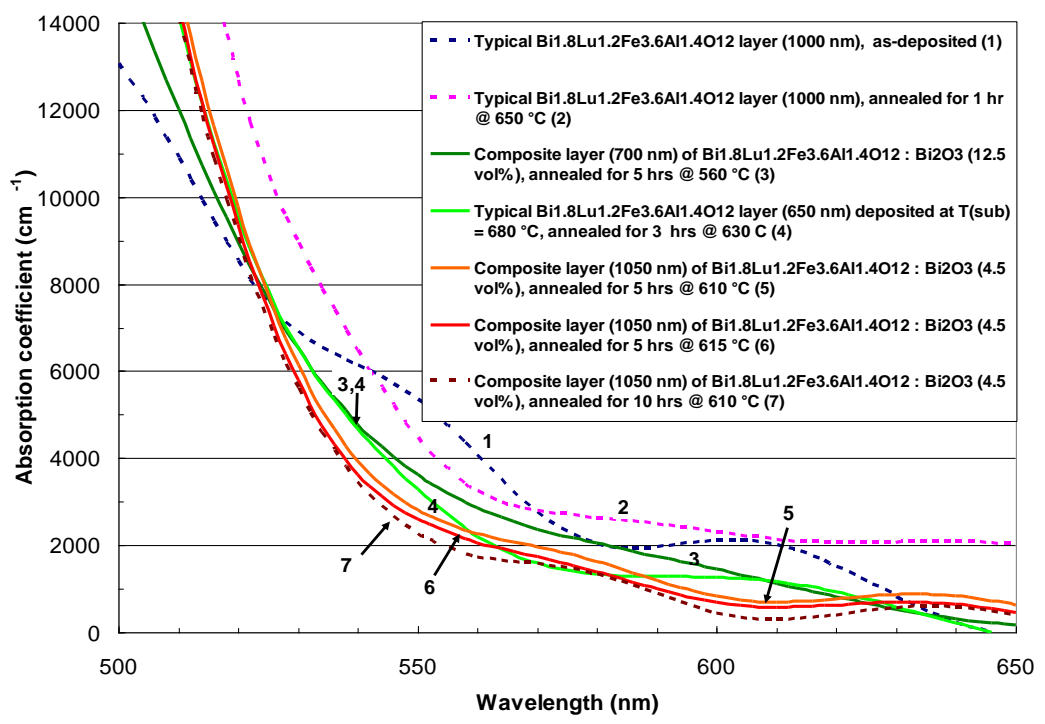

Fig. 5. Derived absorption spectra of $\mathrm{Bi}_{1.8} \mathrm{Lu}_{1.2} \mathrm{Fe}_{3.6} \mathrm{Al}_{1.4} \mathrm{O}_{12}$ and several $\mathrm{Bi}_{1.8} \mathrm{Lu}_{1.2} \mathrm{Fe}_{3.6} \mathrm{Al}_{1.4} \mathrm{O}_{12}$ : $\mathrm{Bi}_{2} \mathrm{O}_{3}$ composite films sputtered onto GGG (111) substrates; the excess content of $\mathrm{Bi}_{2} \mathrm{O}_{3}$ and the annealing regimes for the typical garnet and the co-sputtered composite films are mentioned.

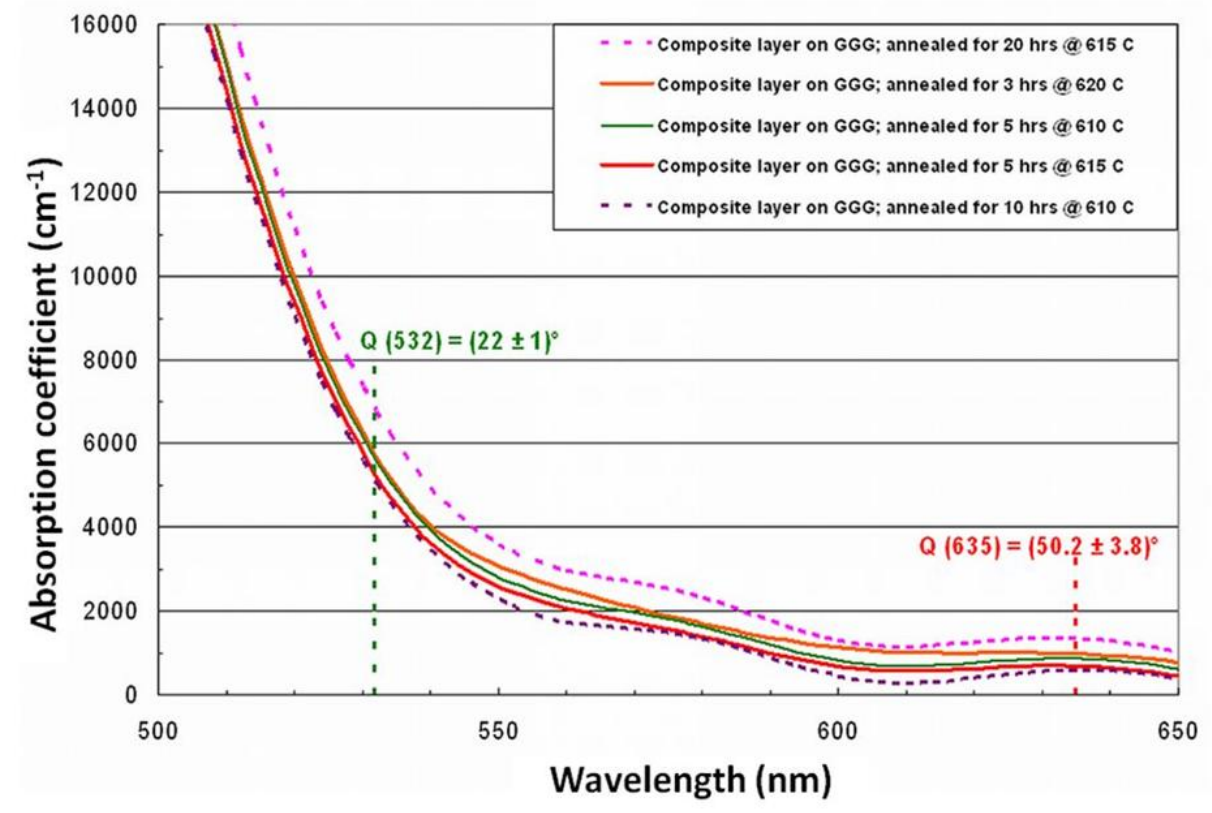

Fig. 6. Derived absorption spectra of $\mathrm{Bi}_{1.8} \mathrm{Lu}_{1.2} \mathrm{Fe}_{3.6} \mathrm{Al}_{1.4} \mathrm{O}_{12}: \mathrm{Bi}_{2} \mathrm{O}_{3}\left(4.5\right.$ vol. \% of excess $\mathrm{Bi}_{2} \mathrm{O}_{3}$ ) garnet-oxide composite films sputtered onto GGG (111) substrates and annealed at $610-620{ }^{\circ} \mathrm{C}$ for different annealing time durations as specified.

Figure 7 shows the summary of the optimization results for the annealing regimes used to crystallize the garnet and garnet-oxide amorphous layers and also the values of best-achieved 
MO figures of merit (data points measured using a $635 \mathrm{~nm}$ plane-polarized laser source). These experimental results provide a reliable source of data for further studies of this interesting material, which has been synthesized for the first time. The best-achieved (so far) MO performance characteristics of our garnet and garnet-oxide composite films for two important wavelengths in the visible spectral region are shown in Fig. 8.

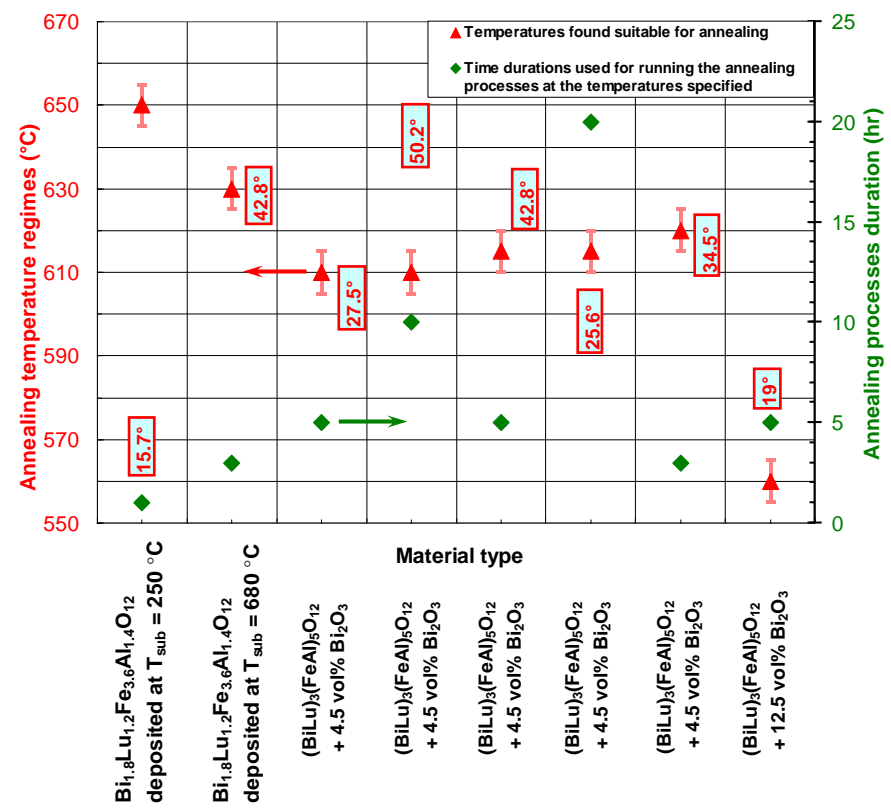

Fig. 7. The data points showing the summary of optimization of annealing temperature and annealing processes duration used to crystallize the typical $\mathrm{Bi}_{1.8} \mathrm{Lu}_{1.2} \mathrm{Fe}_{3.6} \mathrm{Al}_{1.4} \mathrm{O}_{12}$ garnet layer deposited at $250{ }^{\circ} \mathrm{C}$ and $680{ }^{\circ} \mathrm{C}$ substrates' temperature and several composite $\mathrm{Bi}_{1.8} \mathrm{Lu}_{1.2} \mathrm{Fe}_{3.6} \mathrm{Al}_{1.4} \mathrm{O}_{12}: \mathrm{Bi}_{2} \mathrm{O}_{3}$ films of having excess $\mathrm{Bi}_{2} \mathrm{O}_{3}$ onto $\mathrm{GGG}$ (111) substrate.

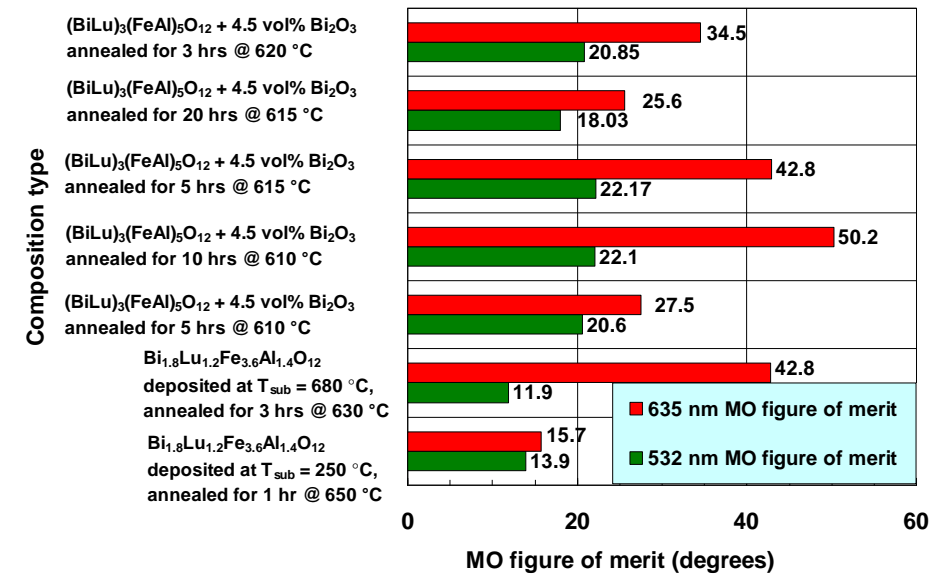

Fig. 8. Measured quality factor in terms of figure of merit of typical $\mathrm{Bi}_{1.8} \mathrm{Lu}_{1.2} \mathrm{Fe}_{3.6} \mathrm{Al}_{1.4} \mathrm{O}_{12}$ garnet layer deposited at $250{ }^{\circ} \mathrm{C}$ and $680^{\circ} \mathrm{C}$ substrates' temperature and several best annealed composite $\mathrm{Bi}_{1.8} \mathrm{Lu}_{1.2} \mathrm{Fe}_{3.6} \mathrm{Al}_{1.4} \mathrm{O}_{12}$ : $\mathrm{Bi}_{2} \mathrm{O}_{3}$ films of having 4.5 vol. \% excess $\mathrm{Bi}_{2} \mathrm{O}_{3}$ onto GGG (111) substrate.

The effects of adding bismuth oxide on the coercivity of the films sputtered onto both GGG and glass substrates were observed, and the results are presented in Figs. 9 and 10. Comparatively, lower coercive force values were measured in composite films sputtered onto 
both types of substrates. We believe that better crystalline quality, lower coercive force values and even higher magnetic field sensitivity can be achieved in our films sputtered onto GGG substrates, if high-substrate-temperature deposition regime is optimized to achieve the conditions suitable for epitaxial-quality layer growth (sputter epitaxy).

Note that two experimental setups were used to confirm the calibration accuracy of the Thorlabs PAX polarimeter that was used for Faraday rotation measurements, namely (i) the direct measurements of optical power transmitted through the sample and the use of an analyzer rotated 45 degrees with respect to the polarisation direction of the incident laser light, under various magnetization conditions, and (ii) a well-calibrated measurement setup based on the detection of polarisation components. The measured Faraday rotations for both setups were in excellent agreement. The Thorlabs PAX polarimeter had a high dynamic range of $70 \mathrm{~dB}$, a broad wavelength range, and an accuracy of $\pm 0.2^{\circ}$.

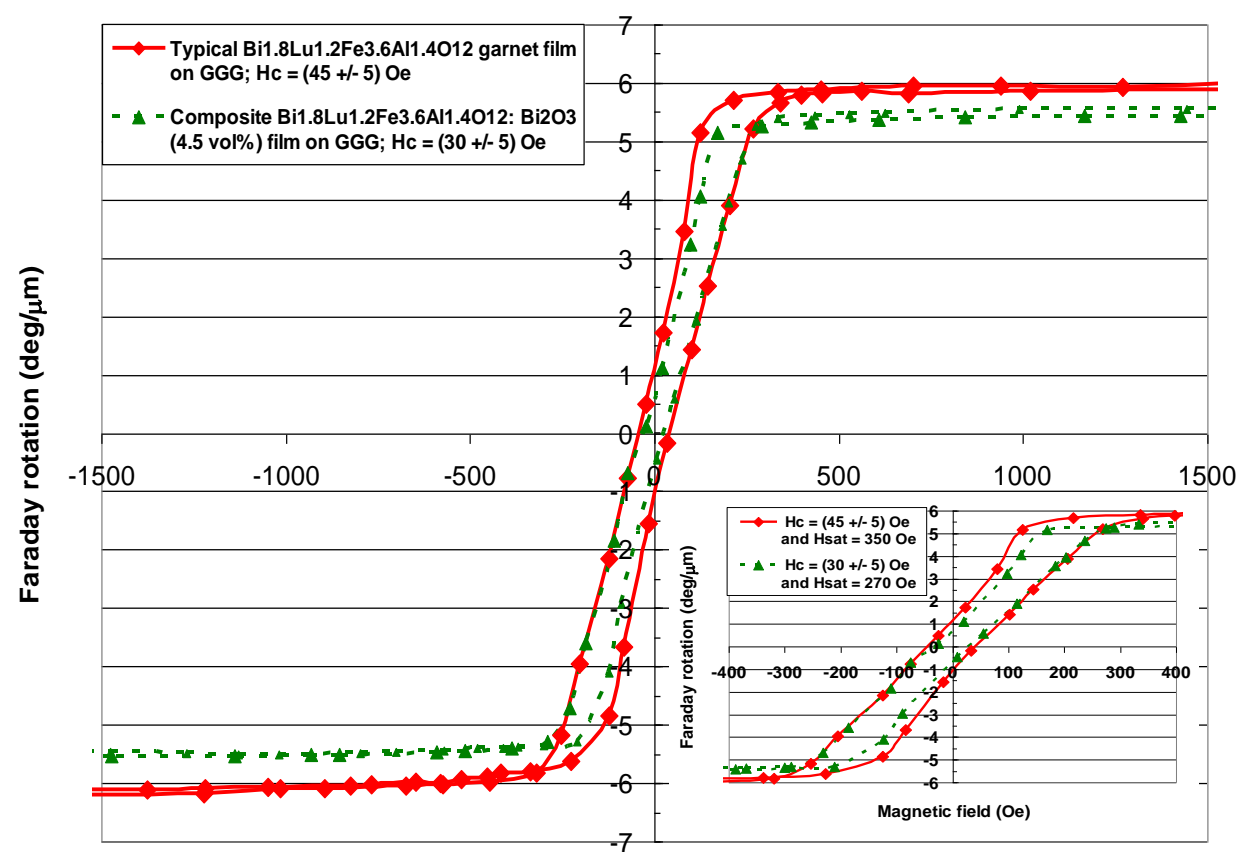

Magnetic field (Oe)

Fig. 9. Hysteresis loops of specific Faraday rotation measured at $532 \mathrm{~nm}$ in sputtered typical $\mathrm{Bi}_{1.8} \mathrm{Lu}_{1.2} \mathrm{Fe}_{3.6} \mathrm{Al}_{1.4} \mathrm{O}_{12}$ layer on GGG (annealed for $1 \mathrm{~h}$ at $650{ }^{\circ} \mathrm{C}$ ) and $\mathrm{Bi}_{1.8} \mathrm{Lu}_{1.2} \mathrm{Fe}_{3.6} \mathrm{Al}_{1.4} \mathrm{O}_{12}$ : $\mathrm{Bi}_{2} \mathrm{O}_{3}\left(4.5\right.$ vol. \%) composite garnet films deposited onto GGG substrate (annealed at $620{ }^{\circ} \mathrm{C}$ for $3 \mathrm{~h}$ ). Insets show the measured coercive force, and saturation field values within the linear ranges of magnetization. 


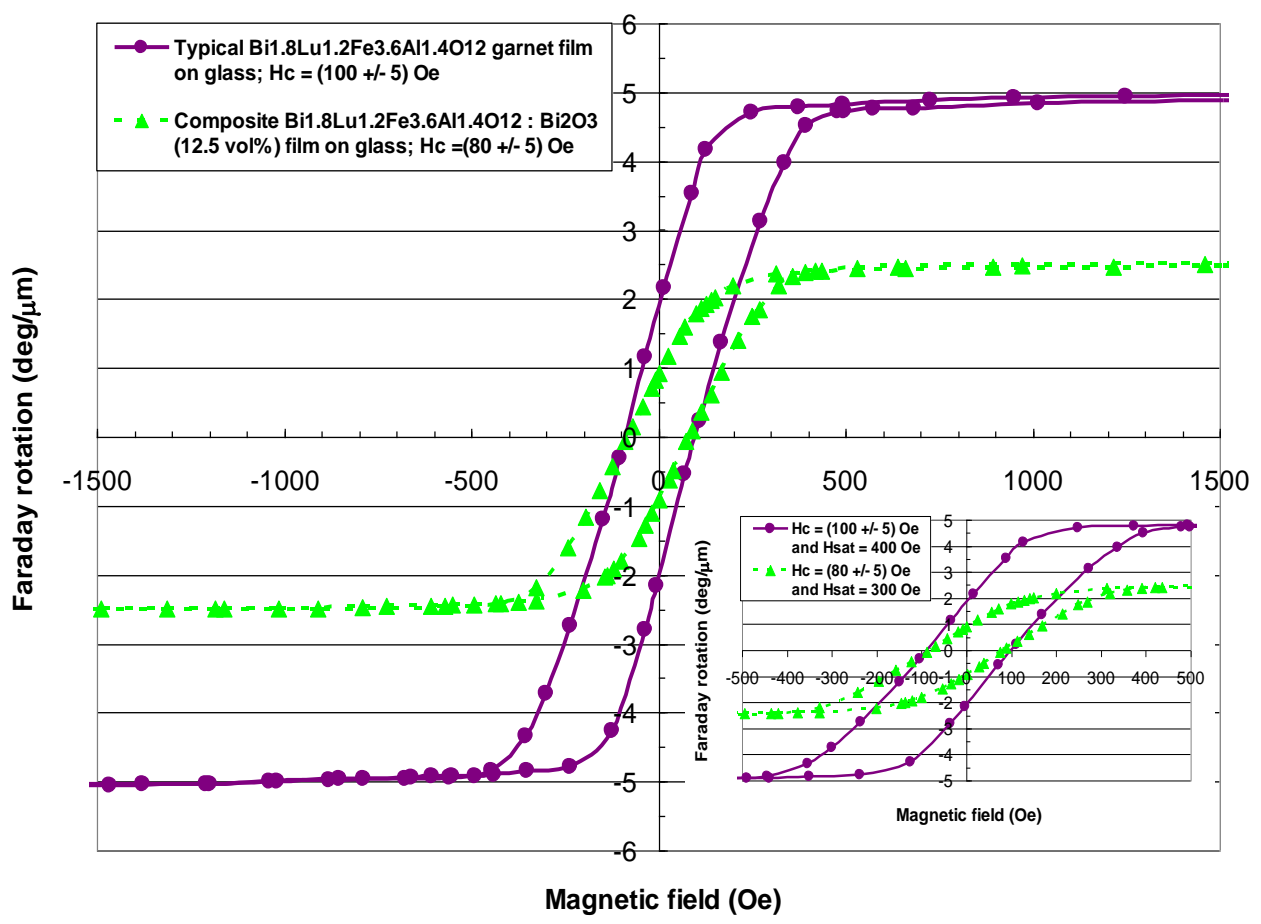

Fig. 10. Hysteresis loops of specific Faraday rotation measured at $532 \mathrm{~nm}$ in sputtered $\mathrm{Bi}_{1.8} \mathrm{Lu}_{1.2} \mathrm{Fe}_{3.6} \mathrm{Al}_{1.4} \mathrm{O}_{12}$ garnet films on glass substrate (annealed for $3 \mathrm{~h}$ at $630{ }^{\circ} \mathrm{C}$ ) and $\mathrm{Bi}_{1.8} \mathrm{Lu}_{1.2} \mathrm{Fe}_{3.6} \mathrm{Al}_{1.4} \mathrm{O}_{12}: \mathrm{Bi}_{2} \mathrm{O}_{3}$ (12.5 vol. \%) composite garnet films deposited onto glass substrate (annealed at $560{ }^{\circ} \mathrm{C}$ for $5 \mathrm{~h}$ ). Insets show the measured coercive force and saturation field within the linear ranges of magnetization.

The surface morphology as well as surface magnetic field distribution topography of $\mathrm{Bi}_{1.8} \mathrm{Lu}_{1.2} \mathrm{Fe}_{3.6} \mathrm{Al}_{1.4} \mathrm{O}_{12}: \mathrm{Bi}_{2} \mathrm{O}_{3}$ composite films having 4.5 vol. $\%$ and 12.5 vol. $\%$ of excess bismuth oxide sputtered onto GGG substrates have been characterized using atomic force microscopy (AFM) and magnetic force microscopy (MFM). Figure 11 shows the scanning probe microscopy inspection results for garnet samples of composition $\mathrm{Bi}_{1.8} \mathrm{Lu}_{1.2} \mathrm{Fe}_{3.6} \mathrm{Al}_{1.4} \mathrm{O}_{12}$ : $\mathrm{Bi}_{2} \mathrm{O}_{3}(4.5$ vol. \%) presented as 3D images of the surface features and surface magnetic field distribution (Fig. 11 (a and b)), and also shows the results for a $\mathrm{Bi}_{1.8} \mathrm{Lu}_{1.2} \mathrm{Fe}_{3.6} \mathrm{Al}_{1.4} \mathrm{O}_{12}: \mathrm{Bi}_{2} \mathrm{O}_{3}$ $(12.5$ vol. \%) film presented as $2 \mathrm{D}$ images (Fig. 11(c, d)). The garnet samples were scanned using semi-contact mode of probe-interaction to obtain the feedback-phase and also the surface topography data simultaneously from the same scan area. The MFM cantilever tip used was cobalt-coated to enable the magnetic-force interaction representation through the phase of the cantilever feedback signal. Nano-crystalline surface microstructure and its associated surface roughness features of the garnet films were observed from the obtained high-contrast images extracted from the measured feedback-phase images and topography data. The magnetic domains structure and the map of magnetic interaction force between the cantilever tip and sample surface were also imaged. 

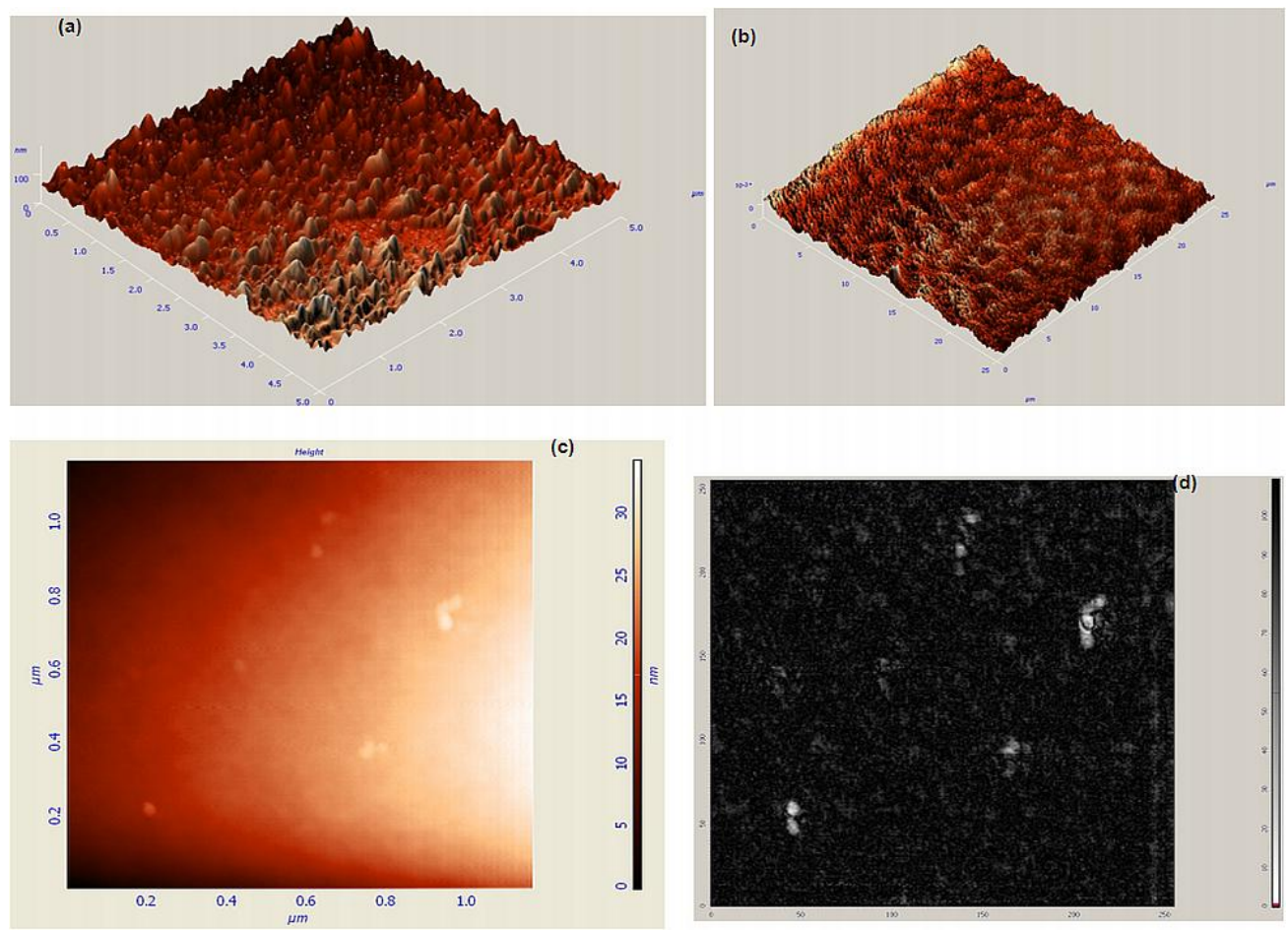

Fig. 11. Scanning-probe (AFM/MFM) images of garnet-oxide composite thin films having 4.5 vol. \% and 12.5 vol. \% extra bismuth oxide sputtered onto GGG (111) substrates. (a-b) 3D images showing the topography $(5 \times 5 \mu \mathrm{m}$ sample area) of a $1050 \mathrm{~nm}$ thick $\mathrm{Bi}_{1.8} \mathrm{Lu}_{1.2} \mathrm{Fe}_{3.6} \mathrm{Al}_{1.4} \mathrm{O}_{12}: \mathrm{Bi}_{2} \mathrm{O}_{3}$ (4.5 vol. \%) composite film annealed for $5 \mathrm{~h}$ at $615{ }^{\circ} \mathrm{C}$ and its surface magnetism features measured across a $25 \times 25 \mu \mathrm{m}$ sample area; (c-d) $2 \mathrm{D}$ AFM topography (c) and (d) an AC magnetic force magnitude map (processed feedback phase image) obtained from a $1.2 \times 1.2 \mu \mathrm{m}$ sample area of a $\mathrm{Bi}_{1.8} \mathrm{Lu}_{1.2} \mathrm{Fe}_{3.6} \mathrm{Al}_{1.4} \mathrm{O}_{12}: \mathrm{Bi}_{2} \mathrm{O}_{3}$ (12.5 vol. $\%)$ nanocomposite film annealed for $5 \mathrm{~h}$ at $580{ }^{\circ} \mathrm{C}$. The black-white color palette of image (d) represents the measured RMS strength of the AC magnetic interaction force between the tip and surface, and the color map shown was obtained using a halved algebraic sum of the phase image data map obtained and its inverted phase image data map, so that only the magnitude of the magnetic interaction force is represented. The white-colored pixels correspond to the minima locations of the magnetic interaction force.

It is important to notice that Figs. 11(a, b) reveal that the addition of extra bismuth oxide results in bismuth-rich MO garnet-phase grains surrounded by transparent non-magnetic bismuth oxide regions. While the measured overall Faraday rotation of the composite film was not improved, the measured overall optical transmission was considerably increased, leading to significant increase in MO figure of merit.

To the best of our knowledge, this is the first report on the properties of this advanced MO material type (garnet-oxide nanocomposites of class $\mathrm{Bi}_{1.8} \mathrm{Lu}_{1.2} \mathrm{Fe}_{3.6} \mathrm{Al}_{1.4} \mathrm{O}_{12}: \mathrm{Bi}_{2} \mathrm{O}_{3}$ ) appearing in the literature published to date. Our work is ongoing and further results, especially on the crystal structure and microstructural details of $\mathrm{Bi}_{1.8} \mathrm{Lu}_{1.2} \mathrm{Fe}_{3.6} \mathrm{Al}_{1.4} \mathrm{O}_{12}$ garnet layers and their co-sputtered nanocomposite derivatives will be reported elsewhere.

\section{Conclusion}

We have studied the RF sputtering deposition and oven annealing processes required for the manufacture of high-performance magneto-optic films of composition types $\mathrm{Bi}_{1.8} \mathrm{Lu}_{1.2} \mathrm{Fe}_{3.6} \mathrm{Al}_{1.4} \mathrm{O}_{12}$ and $(\mathrm{BiLu})_{3}(\mathrm{FeAl})_{5} \mathrm{O}_{12}: \mathrm{Bi}_{2} \mathrm{O}_{3}$ on garnet and glass substrates. The optical, magnetic and magneto-optical properties of a range of highly Bi-substituted lutetium iron-aluminum garnet layers have been characterized in detail and reported for the first time. 
Significantly improved magneto-optical figures of merit have been achieved using the cosputtering bismuth oxide-mixing approach, and the results confirm that this synthesis method is suitable for a wide range of Bi-substituted MO garnet materials. The developed garnet and garnet-oxide thin film materials possess a combination of properties which are highly promising in regard to the future development of garnet waveguides, non-reciprocal integrated-optics components as well as magnetic field imaging and sensing devices.

\section{Acknowledgment}

This research is supported by the Faculty of Computing, Health and Science, Edith Cowan University. We also acknowledge the support provided by the Department of Nanobio Materials and Electronics, Gwangju Institute of Science and Technology (South Korea).

\#147538 - \$15.00 USD Received 13 May 2011; revised 8 Jun 2011; accepted 12 Jun 2011; published 17 Jun 2011

(C) 2011 OSA

1 July 2011 / Vol. 1, No. 3 / OPTICAL MATERIALS EXPRESS 427 